\title{
Desenvolvimento regional adaptado: o caso da Amazônia brasileira
}

\section{GERD KOHLHEPP}

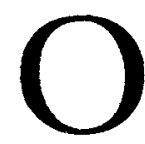

rápido aumento da destruição das florestas tropicais, já previsto há anos por cientistas de organizaçóes ambientais nacionais e internacionais bem como pela população atingida (Sioli, 1983; Goodland \& Irwin, 1975; Fearnside, 1982, 1985; Moran, 1983; Engelhardt \& Fittkau, 1984; Bruenig, 1987; Mahar, 1979, 1989; Ab'Saber, 1989; Valverde, 1989; Kohlhepp, 1976, 1990, entre outros), tornou-se cada vez mais o foco de discussôes em níveis interno e externo ao país. Tais discussóes giram principalmente em torno da Amazônia brasileira, devido aos acontecimentos alarmantes ocorridos naquela região.

No âmbito político a discussão iniciou-se mais tarde, intensificando-se apenas após a Conferência Mundial sobre o Clima, realizada pela ONU em Genebra no ano de 1979.

O ponto de partida para o diálogo político estabelecido foi a problemática da interdependência entre a crescente poluiçáo ambiental por emissóes de gases e a ameaça à atmosfera terrestre, assim como as alterações climáticas daí decorrentes, colocando em perigo a vida do planeta, ou, ao menos, comprometendo seriamente o habitat humano.

No centro desta questão podem ser localizados dois complexos fenômenos:

- a destruição da camada de ozônio na atmosfera;

- o efeito estufa.

A causa para ambos os fenômenos pode ser detectada na liberação de gases em decorrência de atividades humanas.

Responsáveis pelo assim chamado efeito estufa, ou seja, aumento de temperatura na troposfera, identificam-se os seguintes gases de origem antropógena:

- Dióxido de carbono $\left(\mathrm{CO}_{2}\right)$, com cerca de $50 \%$ de participação no efeito estufa, causado por combustíveis fósseis como carvão, petróleo e gás natural, além de queimada de florestas tropicais. 
- Metano com cerca de $19 \%$, liberado por emissóes na exploração de jazidas de gás natural, carvão e petróleo, assim como na agricultura (sobretudo no cultivo de arroz e na pecuária) e em depósitos de lixo.

- Clorofluorcarbono com $17 \%$.

- Outros gases com 14\% (ozônio na troposfera, dióxido de nitrogênio, $\mathrm{H}_{2} \mathrm{O}$, vapor d'água na estratosfera).

Em alguns países industrializados, sobretudo na Alemanha, esforços para a redução dos clorofluorcarbonos, e assim para a preservação da camada de ozônio, já se encontram em avançado estágio devido a medidas voluntárias de redução, específicas a cada produto. No entanto a problemática da emissão de $\mathrm{CO}_{2}$, desencadeadora principal do efeito estufa, ainda se encontra completamente fora de controle. Apesar de iniciados acordos internacionais, os E.U.A., especialmente, negaram sua cooperação.

Os posicionamentos políticos dos países industrializados com relação às crescentes concentraçóes de $\mathrm{CO}_{2}$ na atmosfera, que atualmente apresentam aumento de 0,4 a $0,5 \%$ por ano, causando o aquecimento global com suas graves conseqüêências (elevação do nível do mar etc.), foram rapidamente reduzidos ao problema da liberação de anidridos carbônicos pela queimada de florestas tropicais, quando tal fator tornouse conhecido.

Os países latino-americanos com florestas tropicais, liderados pelo Brasil, protestaram com veemência contra as acusações unilaterais provenientes da Europa e dos E.U.A., quanto a serem responsáveis diretos pelas consequiências globais da mudança climática. Năo se pode negar que, no ano de 1986, os países industrializados causaram aproximadamente $80 \%$ das emissóes globais de $\mathrm{CO}_{2}$ liberadas por combustíveis fósseis, enquanto a participação da América Latina foi de apenas 4,6\% (Deutscher Bundestag = Parlamento Alemão, 1989, p.486).

Em junho de 1980, na Conferência Mundial The changing atmosphere realizada em Toronto, foi recomendado ao setor energético a redução de $20 \%$ das emissóes mundiais de $\mathrm{CO}_{2}$ até o ano de 2005 e de pelo menos $50 \%$ até 2050 .

Esse procedimento significaria uma taxa de reduçáo maior que $50 \%$ nos países industrializados, tendo em vista que as necessidades de desenvolvimento dos países do Terceiro Mundo não permitiriam tal nível de reduçáo.

Relativamente à participaçăo das queimadas de florestas tropicais 
e emissão de $\mathrm{CO}_{2}$, os dados científicos são ainda bastante divergentes, variando entre 7 e $32 \%$ da quantidade liberada pelos combustíveis fósseis. A América do Sul é responsável por $40 \%$ do $\mathrm{CO}_{2}$ liberado nesse tipo de atividade, classificando-se o Brasil em primeiro lugar (Deutscher Bundestag, 1989, p.538; 1990, p.433-434).

Sem menosprezar a parcela de responsabilidade da destruição das florestas tropicais nas temidas mudanças climáticas, constata-se que a ligação entre a questão dessas florestas e a catástrofe climática global poderia ter sido feita de modo mais estratégico sob o ponto de vista da política de desenvolvimento.

Desde o início, as estratégias relativas ao diálogo ambiental quanto às florestas tropicais deveriam ser mais voltadas à persuasáo, no sentido de mostrar que as conseqüências da destruição das florestas far-se-ão sentir primeiro e mais fortemente em nível regional e nacional.

Apenas atualmente vem sendo salientado, no âmbito da discussão ambiental, que a destruição das florestas tropicais não constitui somente um problema climático de alcance global, ou seja, um problema ecológico (sobretudo no tocante à perda de recursos genéticos), mas também social e, a médio e longo prazos, econômico dos países e das populaçóes atingidas.

Principalmente as reaçóes do governo brasileiro (1985-1990) à discussão internacional sobre a destruição das florestas e sobre as soluçóes para o problema iam desde a rejeiçăo (Sarney: campanba de difamaģão), assim como ocorrera 15 anos antes nas reaçôes dos governos militares relativamente à questáo indígena. As proposiçóes vindas do exterior foram consideradas como intromissóes nos assuntos internos do país e ameaça à soberania nacional $\mathrm{e}$ - mais uma vez - trazida à tona a internacionalização da Amazônia (Kohlhepp, 1977). Créditos atrelados a condiçóes submetidas a controle internacional foram repugnados $\mathrm{e}$ modelos de conversão da dívida que favoreciam a floresta tropical rejeitados. Faltas do governo eram justificadas pelo argumento de que já existiam leis regulamentando a proteção.

Surgimento e reorganização da política ambiental brasileira e o tratamento da problemática da floresta tropical na década de 80

Embora alguns países do Terceiro Mundo - entre eles o Brasil tenham declarado a proteção ambiental como empecilho ao desenvolvimento durante a Primeira Conferência sobre o Meio Ambiente das Na- 
çóes Unidas realizada em Estocolmo em 1972, esta conferência motivou, também no Brasil, um primeiro impulso quanto ao surgimento de atitudes preliminares para uma política ambiental nacional.

A criação da SEMA (Secretaria Especial do Meio Ambiente) em outubro de 1973, durante a fase mais repressiva da ditadura militar, quando questooes ambientais eram tratadas pelo Conselho de Segurança Nacional e pelo SNI (Guimarães, 1989), surpreendeu a opinião pública. No entanto, a instalação da SEMA foi concebida como resposta às críticas internacionais ao Brasil e medida tática para fazer jus ao requerimento formal de medidas de proteçáo ambiental na concessáo de créditos internacionais (Viola, 1988).

Com a criação do SISNAMA (Sistema Nacional para o Meio Ambiente) em 1981 e do CONAMA (Conselho Nacional do Meio Ambiente) estavam estabelecidos o quadro e os parâmetros direcionando a política ambiental brasileira, que agora dispunha de um sistema institucionalizado e dividido verticalmente em diferentes níveis de ação (governos federal, estadual e municipal). No entanto, faltava a disposição política de dispor deste instrumento de maneira eficiente. A SEMA continuava em posição marginalizada e nunca, até a segunda metade dos anos oitenta, chegou a exercer influência nos planos de desenvolvimento do Governo. A problemática ecológica não se tornou fator decisivo nos planos de desenvolvimento governamentais (Guimarães, 1986, 1989).

Em fevereiro de 1989, após a extinçăo dos órgãos IBDF, SUDEPE, SUDHEVEA e SEMA foi criado o IBAMA, como novo órgáo central para o meio ambiente e os recursos naturais renováveis, responsável pela articulação, coordenação, execução e controle da política ambiental nacional. Além disso o IBAMA foi incumbido da execuçăo do PNMA (Programa Nacional do Meio Ambiente), financiado, entre outros, pelo Banco Mundial com 200 milhôes de dólares.

Ante as crescentes discussões em torno do baixo grau de aceitação da legislaçáo ambiental a nível nacional e em função das pressóes externas sobre o governo brasileiro visando melhoria na proteção das florestas amazônicas, ficou estabelecido dever o IBAMA dedicar-se com maior intensidade que seu antecessor - a SEMA - ao controle dos recursos naturais e das atividades econômicas. Esse controle referia-se especialmente ao combate a desmatamentos ilegais e ao impedimento do tráfico ilegal de animais silvestres e de peles. Pela primeira vez o IBAMA tentou, numa ampla campanha, reduzir as queimadas na Amazônia ou, pelo menos, fiscalizar o caráter legal destas atividades. 
Ainda que, em vista das imensas dimensōes do território em questáo só se pudesse contar com sucesso restrito relativo a controle, os vôos de inspeção já causaram insegurança considerável junto aos infratores.

Em 1989, no âmbito da reformulação de várias leis, foi também estabelecido que as áreas florestais existentes em cada propriedade deveriam ser cadastradas, para evitar a sua venda com posterior desmatamento. No entanto, há alguns aspectos que até hoje permanecem obscuros, entre os quais principalmente a discrepância entre regiōes com $50 \%$ de reserva florestal obrigatória (Amazônia) e aquelas com $20 \%$ em áreas extra-amazônicas como, por exemplo, na Mata Atlântica, igualmente ameaçada.

Além dessa tarefa de controle, extremamente difícil de ser efetuada, caberia ao IBAMA a função de rever os planos de aproveitamento de florestas primárias e secundárias além de sintonizá-los com as disposiçôes legais em vigor.

No âmbito das reestruturaçōes administrativas que levaram à criaçáo do IBAMA na fase final do Governo Sarney, estabeleceu-se uma reorientação temática da política ambiental brasileira: o Programa Nossa Natureza, lançando com grandes recursos propagandísticos (Schipulle, 1989) e amplamente discutido na Constituinte. Os objetivos do programa, cujas metas principais foram incluídas na Constituiçăo (Constituinte, 1989; MINTER/IBAMA, 1989), sáo a proteçáo dos grandes complexos ecossistêmicos do Brasil, a organização sistemática da proteção ambiental, a elaboração de estratégias evitando atividades que comprometam a proteçáo, o desenvolvimento da educaçáo ambiental, a conscientizaçáo com relação à questáo ambiental, a organizaçáo de colonização e aproveitamento racional de recursos naturais nos parâmetros de ordenaçáo territorial a ser estabelecida, a regeneraçáo de ecossistemas comprometidos pela atuaçáo do homem e, finalmente, baseada na proteção dos recursos naturais, a proteçáo dos grupos indígenas e extrativistas (Diário Oficial, 13.10.1988).

Assim como seus antecessores SEMA e IBAMA, também o Programa Nossa Natureza deve ser compreendido, mais do que uma concepçáo autônoma, como reaçăo a veementes críticas feitas por instituiçóes internacionais, governos estrangeiros e organizaçōes nẩo-governamentais (ONGs), bem como a críticas formuladas em âmbito nacional, especialmente por parte do movimento ambientalista brasileiro em formaçáo (Padua, 1989; Padua et alii, 1987). O caráter estratégico da questáo ambiental foi também percebido pelos militares brasileiros, já que, antecedendo a proclamação do Programa Nossa Natureza houve na 
mídia nacional polêmica discussão de militares de alto escalăo sobre a internacionalização da Amazônia e suas possíveis implicaçóes para a segurança nacional. Mesmo para os membros civis do Governo, como o Presidente do IBAMA, o conteúdo do programa permanecera em parte desconhecido até a data de seu lançamento (Jornal do Brasil, 7.4.1989).

Na Constituição de 1988 a problemática ambiental é tratada no Artigo 225. Nele, reconheceu-se o direito de todos a um meio ambiente ecologicamente equilibrado e a uma qualidade de vida sadia, sendo asseguradas pelo Estado a implementação das medidas necessárias. Embora estas afirmações guardem caráter extremamente geral e as modalidades da implementação permaneçam em aberto, o Artigo foi, após duras discussōes na Constituinte, incluído na Constituição. Aos grupos ambientalistas brasileiros cabe grande parte da responsabilidade pela inclusão inédita de disposições sobre o meio ambiente na Constituição da República.

O Artigo 225, parágrafo $4^{\circ}$, reza que a Floresta Amazônica, a Mata Atlântica, a Serra do Mar, o Pantanal e a Zona Costeira serão doravante considerados Património Nacional, o que equivale dizer encontrarem-se sob proteção ambiental e sua utilização deve ocorrer "dentro de condiçōes que assegurem a preservação do meio ambiente".

No entanto, a expressão Patrimb́nio Nacional não se encontra definida até o presente momento, tampouco as delimitaçóes geográficas específicas das regióes em questão, muito menos ainda ocorreu a elaboração de planos de aproveitamento. Não existe também legislação específica para manejo ecológico dos solos.

As diversas tentativas de elaborar divisão detalhada do espaço físico e econômico de regióes como a Amazônia devem seguramente ser vistas como estudos científicos fundamentados visando a política regional. Os esboços para ordenação territorial da regiáo amazônica, apresentados por várias instituiçōes (entre outras FAO, IBGE) até o momento, utilizaram critérios diferentes (zoneamento agro-ecológico, ecológicoeconômico etc.), em parte completamente incompatíveis com a realidade regional (Ab'Saber, 1989). Essas tentativas demonstram o dilema central da aplicação de disposições legais no âmbito ambiental e a impossibilidade de seu controle quando há conflitos de interesse.

Devido a enormes problemas econômico-sociais o Brasil encontrava-se em situação praticamente inviável ao final do Governo Sarney. Apesar de todas as declaraçóes oficiais e do vasto catálogo de leis e medidas constantes do Programa Nossa Natureza, a contradição entre aspi- 
ração e realidade no campo ambiental cresceu consideravelmente. Apenas um terço das verbas federais que, com cerca de 180 milhões de dólares, já eram bastante reduzidas, estava disponível no início de 1989. Faltava vontade política para realizar as medidas necessárias relativas à proteção das florestas tropicais.

\section{Diretrizes da política ambiental no Governo Collor a partir de março de 1990}

Empossado desde março de 1990 o Governo Collor, em seus primeiros pronunciamentos sobre o programa de governo, soube incluir de maneira astuta em suas estratégias parte significativa das exigências de cientistas e integrantes de grupos ambientalistas, assim como temas em voga na discussão pública.

Foram mencionadas como premissas para futuras medidas, entre outras (Governo Collor, 1990):

- desenvolvimento econômico năo deve mais ser tratado independentemente da proteção ambiental;

- proteção ambiental, a que se atribui grande importância, deve atuar como fator de coesão entre ministérios, secretarias, setor privado e grupos ambientalistas em busca de uma solução;

- estrutura administrativa de órgáos federais encarregados da questão ambiental deve ser reorganizada para um trabalho mais eficiente.

Para tanto foi criada, como órgão político central, a Secretaria do Meio Ambiente (SEMA), diretamente subordinada ao Gabinete Presidencial, cuja função seria dirigir a elaboração de uma concepção de política ambiental e a coordenação das medidas ambientais, além do controle de sua aplicação através do IBAMA.

A continuidade do Programa Nacional do Meio Ambiente (PNMA) seria garantida, sob o ponto de vista financeiro, por um fundo nacional para o meio ambiente. A descentralização da política ambiental seria promovida através de ampliação sucessiva dos órgáos ambientais em nível estadual e municipal. As idéias das $O N G$ deveriam ser inseridas na discussão pelo estabelecimento de metas regionais e setoriais da política ambiental.

Os problemas ambientais deveriam ser melhor esclarecidos para o público através dos Estudos de Impactos Ambientais (EIA) e de sinópticos Relatórios dos Impactos sobre o Meio Ambiente (RIMA), os quais auxiliariam a pesar e classificar os riscos ambientais. 
O programa de proteção ambiental do Governo Collor tem enfoque regional que abrange os ecossistemas brasileiros mais importantes, incluindo as Florestas Amazônicas e a Mata Atlântica. Paralelamente foi ainda desenvolvido um enfoque setorial, em que são elaboradas diretrizes e exigências de participação em uma política ambiental eficaz para cada ministério.

Para garantir a proteção dos ecossistemas a SEMA também pretende, junto com os governos estaduais, elaborar planos de zoneamento agro-ecológico e econômico, conduzidos por desenvolvimento de orientação ecológica em função da populaçáo regional. O setor público terá como diretriz básica privilegiar o financiamento de projetos ecológicos.

O destaque, na opiniăo pública nacional e internacional coube à nomeação de José Lutzenberger para Secretário do Meio Ambiente, o qual se tornara conhecido como um dos iniciadores do movimento ecológico no Brasil. Sendo um dos críticos mais violentos da política ambiental brasileira (Lutzenberger, 1977, 1987), estendendo esta crítica também às constelaçóes de poder em torno dos candidatos à Presidência e às suas idéias desenvolvimentistas no período eleitoral, a indicaçáo de seu nome para o mais alto cargo no campo ambiental foi grande surpresa.

Com a nomeação do mais conhecido crítico, a nível internacional, da política ambiental dos governos brasileiros, Collor manifestou sinais de cooperação em direçáo ao exterior, tanto no âmbito governamental quanto no das $O N G s$, e ao movimento ecológico nacional. Tal decisão, astuta e corajosa, certamente deve ser considerada no contexto das ofertas internacionais para financiamento da proteçáo das florestas tropicais, enquanto a 3a Conferência Mundial do Meio Ambiente realizada em junho de 1992, sediada no Brasil, ofereceu amplas possibilidades propagandísticas internacionais ao Presidente.

Após dois anos de governo os problemas financeiros ultrapassam em muito as prioridades ambientais anunciadas. Várias medidas ainda não foram colocadas em prática, ou foram adiadas, em funçăo de problemas tanto de ordem financeira como de recursos humanos.

Relativamente às estratégias de proteção às florestas amazônicas, deve-se ressaltar como fator positivo o corte de incentivos fiscais para projetos problemáticos do ponto de vista ecológico, atingindo sobretudo estabelecimentos pecuários. O IBAMA também anuncia reduçăo de $27 \%$ das queimadas na Amazônia em 1990. Por outro lado o governo ainda não revogou os planos militares para a fronteira setentrional, no âmbito do Programa Calha Norte. Neste aspecto, revelam-se contradiçóes tão 
fundamentais quanto nos pronunciamentos do chefe da SEMA a respeito dos conflitos de interesses na Região Grande Carajás e da problemática do carvão vegetal, até hoje insolúvel.

Atualmente, o programa de austeridade monetária autoproclamado do Governo Collor não permite a realizaçăo das medidas ambientais planejadas. Em vista da situação econômica extremamente precária, fica claro que o programa de saneamento financeiro dará tratamento secundário - se é que dará - às prioridades estatais para a proteção ambiental incluídas em suas declaraçóes iniciais. Tal situaçáo aumenta a necessidade de apoio internacional dirigido à proteção das florestas tropicais, hoje encontrando grande disposição ao diálogo por parte do Brasil.

\section{Iniciativas internacionais para a proteção de Floresta Amazônica}

As medidas internacionais abrangem amplo espectro e vão desde planos de diretrizes globais até projetos isolados. Nelas participam diversos governos e organizaçōes governamentais bilaterais, além das ONGs nacionais e internacionais.

O mais importante acordo internacional formalizado neste sentido foi o Plano de Afão para o Manejo Florestal nos Trópicos (TFAP - Tropical Forestry Action Plan), lançado por iniciativa da FAO em 1985 e apresentado ao público internacional por FAO, Banco Mundial, Plano de Desenvolvimento da ONU (UNDP) e World Resources Institute em 1986/87. O TFAP é um plano global, sem caráter de compromisso do ponto de vista do Direito Internacional, que fornecerá diretrizes para elaboraçáo e implementaçáo de estratégias para o setor florestal em nível dos diferentes países com florestas tropicais, funcionando como base para a coordenação dos auxílios internacionais para o desenvolvimento da defesa florestal nos trópicos. A meta deste plano é elaborar, em esforço conjunto, planos de ação nacionais para todos os países e organizaçōes interessados.

Os principais setores de atuação do TFAP são:

- integração da silvicultura e do manejo de solos;

- desenvolvimento da economia florestal e madeireira através de medidas que promovam indústrias florestais e madeireiras ecologicamente adaptadas;

- preservaçăo dos ecossistemas florestais nos trópicos;

- fortalecimento das instituiçóes públicas e privadas (ONGs) envolvidas. 
A avaliação do TFAP na discussão internacional é bastante controvertida: Seus adeptos argumentam que:

- o manejo sustentado de longo prazo das florestas tropicais terá conseqüências positivas (empregos, salários, assistência social);

- o aumento das exportaçōes de produtos florestais acarretará, além do aumento do PIB, melhora na situação cambial dos respectivos países;

- com o aproveitamento econômico a população local desenvolverá interesse pela preservação das florestas.

Os críticos duvidam que estas vantagens possam ser realmente alcançadas; fundamentando-se em experiências negativas com planos nacionais já existentes e ponderando principalmente que:

- o TFAP concentra-se sobretudo em aspectos silviculturais, especialmente no aproveitamento industrial das florestas, ou seja, dando prioridade ao interesse comercial em detrimento da defesa florestal;

- a implementação do TFAP implicará emprego de recursos financeiros consideráveis, o que sugere a ocorrência de efeitos negativos, entre os quais deve ser incluída a consolidaçáo das estruturas de poder existentes;

- os povos da floresta e os que dela dependem não foram devidamente levados em consideraçáo.

O principal argumento desses críticos está ligado à idéia do manejo sustentado de longo prazo que, através da exploração econômica, contribuiria para a destruiçáo das florestas tropicais (cf., por exemplo a discussão entre Oberndörfer, 1989a e b; Lamprecht, 1989; Bruenig, 1989; Weidelt, 1989). Outro dos pontos fracos do TFAP refere-se ao fato de não estar vinculado a medidas como reforma agrária, planejamento familiar e problemática do endividamento.

Até setembro de 1990 havia, por parte do Brasil, apenas pedido de informações, enquanto 23 países já haviam elaborado planos nacionais e outros 35 realizado estudos sobre o setor florestal.

O Acordo Internacional sobre Madeiras Tropicais (ITTA) refere-se à matéria prima, assinado por 36 países produtores e 34 consumidores em 1983, e visa, seguindo a sua funçáo, primordialmente a metas econômicas. No entanto, objetiva também a garantia de aproveitamento e proteçăo das florestas tropicais e sua diversidade genética, a fim de preservar o equilíbrio ecológico das respectivas regióes. Os 44 países-membros (incluindo o Brasil) representam $75 \%$ do total de florestas tropicais existentes e realizam $95 \%$ do comércio mundial de madeiras tropicais. Dessa forma certamente o ITTA não constitui base para a política mundial de proteção das florestas tropicais. 
Entre as atividades de organizaçóes internacionais devem ser mencionados sobretudo a UNESCO e seu programa $O$ Homem e a Biosfera ( $M A B)$, iniciado em 1971, que desencadeou pesquisas sobre os impactos das atividades do homem sobre os diferentes ecossistemas. Atualmente os ecossistemas florestais tropicais e subtropicais formam o centro de interesse neste sentido.

A UNESCO pretende desenvolver principalmente as concep̧̧óes de manejo agrícola sustentado, conciliando noçōes tradicionais e condiçōes de vida da populaçáo com os sistemas ecológicos. É também de seu interesse o reflorestamento e a regeneração de ecossistemas degradados nos trópicos úmidos.

Aqui a concepção das Reservas da Biosfera, que ressalta a proteção do meio ambiente e das espécies (UNESCO, 1984; v.Droste \& Dogsé, 1990), prevê a criação de uma rede internacional de áreas de proteçăo que demonstre o valor das medidas conservacionistas, procurando atingir a inter-relação entre proteção ambiental, pesquisa, manejo de solos, controle ambiental, formação de profissionais, educação ambiental e participação da população atingida.

A proteção às florestas tropicais é também ambicionada pelo World Heritage Trust-Fond, que visa a inserção harmônica do homem na natureza, cuja base legal é a Convenfáo para a Preservafão da Heranf̧a Cultural e Natural do Homem, elaborada pela UNESCO em 1973. O objetivo desse fundo é a preservação de áreas de importancia fundamental que já formam parques nacionais dentro das respectivas legislaçōes nacionais. Neste contexto discute-se criaçáo de pagamentos compensatórios aos países com florestas tropicais pela não-utilização destas florestas (Deutscher Bundestag, 1990, p.617-618); Oberndörfer, 1989a).

No âmbito das iniciativas governamentais internacionais cabe especial importância às reunióes de cúpula do Grupo dos Sete:

- Reunião de Toronto (junbo de 1988)

Primeira declaração sobre a necessidade de preservação das florestas tropicais a nível dos chefes de governo.

- Reunião de Paris (junho de 1989)

A questão ambiental, especialmente a preservaçăo das florestas tropicais, recebe prioridade máxima por parte dos chefes de governo. Os países do grupo comprometem-se a apoiar financeira e tecnicamente as iniciativas dos países com florestas tropicais. A iniciativa alemã foi tomada como base para a ação comunitária neste setor. Outra afirmaçáo da Reuniáo de Paris foi a inclusáo de aspectos ambientais nas decisóes econômicas do futuro. Neste contexto também 
foi mencionada a reduçáo de dívidas em funçáo de medidas ambientais, beneficiando os países altamente endividados.

- Reunião de Houston (junbo de 1990)

A Alemanha confirma seu papel de vanguarda no que toca à preservação de florestas tropicais. O Banco Mundial, a Comissão da CE e os chefes de governo do Grupo dos Sete oferecem ao Brasil um programa piloto para a preservaçáo florestal, aceito em seus princípios pelo Governo Collor.

Enquanto as iniciativas da $\mathrm{CE}$ no âmbito direto da protefão de florestas tropicais - exceçăo feita a alguns projetos florestais - ainda não tenham abandonado o estágio do esboço (mesmo na iniciativa com relaçāo a Grande Carajás), a República Federal da Alemanha já se destacou através de auxílios financeiros em diversos níveis.

\section{A contribuição da Alemanha para a proteção das florestas tropicais no Brasil}

Em fins de 1989 o governo brasileiro, o Banco Mundial e o governo da República Federal da Alemanha concordam em financiar o Programa Nacional do Meio Ambiente (PNMA), realizado pelo IBAMA.

Os objetivos do PNMA, em cujo planejamento também foram ativamente integradas as ONGs nacionais e internacionais, são:

- a garantia de reservas florestais, especialmente na regiāo amazônica: parques nacionais, reservas biológicas e ecológicas etc., através da criação de Unidades de Conservação (Padua, 1988);

- a preservação de ecossistemas em perigo, como Mata Attântica, manguesais, Pantanal etc.;

- o fortalecimento das Secretárias do Meio Ambiente em nível federal e estadual.

Para a primeira fase do PNMA foram colocados à disposição 200 milhōes de dólares (Banco Mundial, 58\%; Brasil, 23\%; Alemanha, $19 \%)$.

Segundo informações do BMZ (Ministério da Cooperação Econômica), a parcela alemã (63,5 milhŏes de marcos concedidos em 1988 e 1989) é composta de 60 milhóes para a cooperaçăo financeira (50\% empréstimos e $50 \%$ doaçóes) e de 3,5 milhōes para a cooperação técnica, a serem empregados sobretudo para garantia de reservas florestais (30 milhóes), preservação da Mata Atlântica no Estado de São Paulo (30 milhóes) e fortalecimento do IBAMA (3,5 milhöes).

Outros 40 milhões (doação) foram concedidos em 1990, objeti- 
vando medidas para a utilização ecológica de recursos florestais na região amazônica. No período de 1991 a 1993 foi aprovada nova doaçáo no valor de 150 milhóes de marcos, significando que até 1993 a Alemanha colocará $\mathbf{2 5 0}$ milhóes de marcos à disposiçáo do Brasil para a proteção de suas florestas tropicais.

O financiamento alemáo concentra-se em geral sobre zonas de proteção e parques florestais, e florestas residuais no estado de São Paulo.

Há, no Brasil, centenas de zonas de proteçăo florestal, tanto em âmbito federal quanto estadual, que ainda não receberam a devida proteção. Até 1993 intenciona-se garantir e consolidar 50 das 100 zonas de proteção sob jurisdição federal, selecionando-se as mais ameaçadas, das quais $75 \%$ (cerca de $80.000 \mathrm{~km}^{2}$ ) encontram-se na Amazônia. Trata-se sobretudo da demarcaçáo dos territórios e da instalação de um sistema de controle eficiente. Além disso está prevista a elaboração de um instrumentário alternativo de proteção para cinco das áreas especialmente ameaçadas (entre elas o Parque Nacional Pacaás Novas e a Reserva Biológica Guaporé em Rondônia) e uma contribuiçăo para o sistema nacional de zonas de conservaçáo SINUC (informaçóes do BMZ).

No caso das florestas nacionais, diferentemente das zonas de proteção florestal, trata-se de questóes de aproveitamento produtivo, ou seja, formas de utilizaçáo sustentadas e não-destrutivas.

As reservas extrativistas deverão ser instaladas para grupos autóctones, visando a utilizaçáo tradicional e ecológica. Um dos grupos beneficiados será o de seringueiros, que ocupa partes da Amazônia há mais de 110 anos. A preservação e consolidação das reservas extrativistas é importante contribuição para a proteção das florestas.

Segundo informaçóes do $\mathrm{BMZ}$, a mais recente concessão de 150 milhöes de marcos deverá apoiar, entre outros, o reflorestamento em áreas degradadas na Amazônia, um dos problemas centrais e extremamente difícil de ser solucionado. Ao mesmo tempo, deverão ser tomadas medidas para a preservação da Mata Atlântica fora do Estado de Sáo Paulo. Finalmente está prevista a participaçáo do financiamento da segunda fase do PNMA, com ampliação das reservas florestais na Amazônia (1988/93).

Todas estas medidas e propostas concretas foram tomadas para encorajar o Brasil a forçar a criação dos devidos parâmetros legais, institucionais, sociais e econômicos. A participação alemá na elaboração de concepçóes deve ser vista no contexto de acordos internacionais para a 
proteçáo das florestas tropicais, incluída ainda a troca de dívidas externas por medidas de proteçáo ambiental (debt-for-nature-swaps).

A comissão Parlamentar de Inquérito Prepenfão para a proteção da atmosfera, do Deutscher Bundestag, constituída por representantes de todos os partidos que compóem o parlamento alemão e por pesquisadores apresentou, após três audiências com participação internacional em 1989 e um ano de debates, incluindo as ponderações de vários especialistas, 0 seu $2^{\circ}$ Relatório ao Parlamento Alemão, dedicada à protefão de florestas tropicais: uma meta prioritária internacional (Deutscher Bundestag, 1990).

Com base em detalhado levantamento de causas e dimensão da destruiçáo das florestas tropicais, foi aconselhado um amplo espectro de medidas, incluindo diversas estratégias políticas, calibradas e concretizadas, em nível nacional e internacional. As propostas para a atuaçăo do Parlamento Alemão seráo submetidas a votaçăo no Parlamento.

\section{Condiçóes preliminares para o desenvolvimento regional ecológico na Amazônia}

Em vista das novas propostas ambientais do Banco Mundial, o Governo Collor aprovou expressamente as iniciativas internacionais para a proteção das florestas tropicais e sinalizou afirmativamente sua cooperação (Goodland, 1990). Mesmo assim, as grandes expectativas surgidas em vista da reorganizaçáo dos órgáos estatais não foram correspondidas. A SEMA e o IBAMA, que funcionariam como órgãos executores no setor do meio ambiente, ainda se encontram em fase de reestruturação e serăo confrontados com uma gama de funçóes extraordinariamente difíceis.

Devido à complexa problemática o IBAMA não se encontra em condiçōes de apresentar, a curto prazo, projetos fundamentados que correspondam às exigências dos órgãos financiadores internacionais (informação pessoal do presidente do IBAMA em 4.10.1990). Certamente esse procedimento ocasionará atrasos na elaboraçáo de acordos bilaterais e internacionais. Da mesma maneira ocorrem atrasos na implantação da descentralização das atividades do IBAMA, devido a questốes de ordem política e pessoal.

Além disso, os governadores de alguns estados - Amazonas, por exemplo -, praticamente fizeram declarafóes de guerra ao planejamento ambiental da Federaçáo, procurando impor seus interesses regionais e 
comerciais particulares sem qualquer colaboraçáo com as tentativas do governo federal.

A participação cada vez maior de organizaçōes não-governamentais (ONGs) nas atividades dos órgãos ambientais constitui inovação ma política ambiental brasileira. Isto vale para a discussão do planejamento, e igualmente quanto a elaboraçáo de soluçóes para certas regioóes (entre outras, concepşáo de reservas extrativistas). Enquanto em nível político foram alcançados consideráveis sucessos (parcialmente em cooperação com ONGs estrangeiras) na denúncia de projetos de desenvolvimento nocivos através de protestos, trabalho de publicidade e elaboraçáo de projetos alternativos, poucas ONGs brasileiras encontram-se em condições financeiras, institucionais e devidamente habilitadas para poder aplicar concepçóes de projetos praticáveis.

Como ainda não foi verificada qualquer coordenação entre as atividades ambientalistas e as $\mathrm{ONG}$ no Brasil, a tendência mais recente é um processo de monopolização das atividades nas mãos de alguns grandes grupos. É o que ocorre, por exemplo, no chamado Consórcio agrupamento de cerca de uma dúzia de ONGs - visando a transformação de parcelas da dívida externa em projetos ambientalistas, ou sua utilização no fortalecimento institucional das referidas organizaçóes. A verba requerida para esses projetos até meados de 1990 , no âmbito do programa debt-for-nature, alcança aproximadamente 360 milhŏes de dólares.

Devido ao crescente entrelaçamento das atividades neste setor, ultimamente $o$ apoio às organizaçóes ambientalistas tem aumentado. Assim, como exemplo, por parte do movimento independente dos seringueiros que, após a morte de seu líder - Chico Mendes - em dezembro de 1988, passou a ter papel destacado na discussão pública, do mesmo modo que organizaçóes indígenas e círculos eclesiais progressistas.

São amplamente conhecidas as causas da destruição das florestas, decorrentes de medidas de planejamento regional fracassadas, as quais conferiam à periferia amazônica apenas uma funçáo complementar em relaçăo ao centro, e de processos espontâneos cada vez mais intensos que foram, em parte, ocasionando degradaçóes irreversíveis (Kohlhepp, 1987a, 1991b):

- pecuária em latifúndios e especulaçáo fundiária agressiva;

- megaprojetos agrícolas e florestais;

- colonizaçáo agrícola de pequenos produtores com crescente descontrole na apropriaçáo da terra;

- projetos industriais e de mineração; 
- alta mobilidade da população e efeitos de irradiação de desenvolvimento das cidades (spread-effects);

- aproveitamento energético da biomassa (produçáo de carvấo vegetal);

- aproveitamento energético através da instalação de usinas hidrelétricas com grandes barragens.

Salienta-se não ser somente interna a natureza destas causas, mas que elas são, em diferentes graus, condicionadas e dependentes de fatores externos (Nitsch 1989).

Sob pressão do crescente agravamento no quadro de destruição das florestas amazônicas e diante da escalada da concorrência pela utilização do solo, manifestada de maneira cada vez mais violenta, e da magnitude das consequiências ecológicas em nível regional e global, urge a tomada de medidas diretas e indiretas para a protefão das florestas tropicais. Para a sua realização torna-se necessária a ajuda financeira internacional e a manifestação de disposiçáo política para a sua ampliaçáo, na maioria dos casos, ainda aguardada, sobretudo por parte do atual governo brasileiro.

Desnecessário frisar que a lista de medidas a seguir relacionadas compreende um programa de urgência em todos os seus componentes; entretanto, não terá chances de ser imediatamente realizado ou inteiramente financiado.

Medidas politicas diretas para a preservação das florestas amazbnicas (em combinação com medidas sócio-econômicas e ecológicas adaptadas):

- renúncia a projetos de implantação de grandes rodovias de penetração;

- redução de interesses especulativos na Amazônia através do corte de benefícios fiscais diretos e daqueles destinados a projetos de desenvolvimento social e ecologicamente inadaptados em áreas de floresta tropical (Binswanger, 1987) (em parte já realizado);

- interdiçáo da implantaçăo de grandes projetos de pecuária em áreas desmatadas (já ocorrido);

- embargo à implantaçáo de novos projetos de colonizaçáo agrícola com sistemas tradicionais (rotaçăo de terras), impedindo assim o avanço da frente pioneira;

- consolidaçăo de projetos de colonização agrícola já existentes através da introduçáo de metodologia de ecodesenvolvimento (Sachs, 1980), como economia agroflorestal em pequenos projetos adaptados a fim de garantir a sustentabilidade a longo prazo;

- reavaliaçáo dos impactos ambientais e sociais de grandes projetos em andamento e tratamento restritivo para novas autorizaçóes, mesmo 
de projetos parciais. Em todos os casos é necessária reavaliação dos custos. Precisam ser incluídos custos ecológicos e sociais e recalculada a rentabilidade a longo prazo;

- apoio a pequenos projetos para aproveitamento da energia hidrelétrica e a projetos de emprego de fontes energéticas alternativas;

- redução da mobilidade dos garimpeiros (cerca de um milhão e meio na Amazônia) a fim de evitar destruição florestal, ameaça ao espaço indígena e contaminação dos rios pelo emprego de mercúrio na mineração de ouro. Esta medida constitui um dos maiores desafios à Federação e aos Estados, como pôde ser verificado no caso dos enfrentamentos no território Yanomami em Roraima;

- definição territorial, implantação, garantia e controle constante de áreas de proteção florestal (grandes áreas de floresta primária) e parques nacionais em regiōes ecologicamente favoráveis, assegurando ao mesmo tempo a sobrevivência de grupos indígenas em reservas de suficiente extensão. Esta concepção, já existente, precisa ser ampliada através de medidas de segurança e consolidada através de medidas imediatas;

- implantação de reservas extrativistas, seguindo os critérios elaborados em 1985 (Allegretti, 1990). Esta concepção já esta sendo aplicada para os seringueiros independentes que, sendo habitantes tradicionais da regiáo (em parte desde os anos 1870), praticam exploração ecológica não só da havea brasiliensis, mas também de outras espécies da flora. Nesta caso, no entanto, é preciso observar um padráo territorial satisfatório (cerca de 500 hectares por família $=$ densidade populacional de $1 \mathrm{hab} / \mathrm{km}^{2}$ ), assim como estrutura organizacional (cooperativa). A questão da rentabilidade de reservas extrativistas deve partir do raciocínio de que economia de subsistência e reduzidas possibilidades de plantar cash-crops (forte dependência do preço da borracha) ainda são melhores que expulsão e migração às cidades saturadas;

- elaboração e aplicaçáo de uma concepção de aproveitamento do espaço diferenciada regional, ecológica e socialmente, incluindo participação e defesa da população em questáo no sentido de responsabilidade social. $E ́$ imprescindível desenvolver modelos de aproveitamento dé solo em funçáo dos grupos atingidos e da populaçáo de baixa renda;

- reflorestamento de regiōes desmatadas e degradadas com espécies nativas e fortalecimento da pesquisa neste setor (IEA, 1990);

- intensificação de programas e projetos de pesquisa direcionadas para o levantamento das interaçóes homem-meio ambiente. 


\section{Medidas a serem tomadas fora da Amazônia}

As chances de realização de desenvolvimento regional ecológico e socialmente adaptado da Amazônia devem aumentar consideravelmente com as medidas retro mencionadas. Cabe especial importância, no entanto, à criaçáo de um quadro político favorável e de medidas econômicas e sociais que se coadunem, objetivando redução das pressões populacional e econômicas sobre a Amazônia, onde o potencial de conflito já assumiu traços violentos.

Entre estas medidas indiretas fora da região, necessárias para a proteção das florestas tropicais, figuram:

- programas agrícolas alternativos nas áreas extra-amazônicas à base de medidas direcionadas de reforma agrária (incluindo a preparação organizacional e a realização de retaliaçóes com auxílio financeiro externo) e implantação de projetos de auxílio para pequenos produtores a fim de reduzir a migração interna e assim também a pressão populacional sobre as regiôes de floresta tropical da Amazônia;

- medidas de política agrícola visando o impedimento dos processos de expulsão da população rural de pequenos produtores, ocorrida no âmbito da modernização da agricultura em outras regiōes brasileiras;

- estas medidas precisam ser acompanhadas de programas de desenvolvimento regional em regióes de colonizaçáo antiga, vinculados a iniciativas para suster a populaçáo rural;

- a nível internacional deve ser reavaliada a questáo da troca de parcelas da dívida externa por medidas ambientais de proteção florestal, concentrada nas ONGs até o presente momento, e aplicada apenas em alguns países (entre outros, Bolívia, Equador, Costa Rica). Banco Mundial, FMI, bancos de desenvolvimento regionais, assim como governos dos países industrializados deveriam dispender esforços para encaminhar a questáo da dívida externa a um órgáo internacional, cuja criação também foi reivindicada pelo Congresso dos EUA (Oberndörfer, 1989a). Ainda fora da Amazônia, as soluçōes alternativas mencionadas e as questóes de retaliação financeira para a renúncia ao aproveitamento devem ser consideradas e vistas como açáo internacional de abrangência global - mesmo além dos limites das florestas tropicais.

O apoio técnico e financeiro internacional a estas medidas básicas devem acarretar - juntamente com a reduçáo dos booms especulativos na Amazônia - visível alívio do stress ecológico e socioeconômico na região.

Em vista dos índices anuais de destruição das florestas tropicais, 
que assumem mundialmente as dimensóes da área da Alemanha, é imprescindível atuaçăo imediata. Para o governo alemáo, que deverá coordenar suas açōes com a Comunidade Européia e com as organizaçóes internacionais, foi elaborado detalhado plano financeiro e cronométrico, com fundamentação científica, por uma Comissão de Inquérito especializada, que confere chance real à manutenção das florestas tropicais.

O atual governo brasileiro já manifestou sua disposição ao diálogo quantos ao tema e, à vista do perigo da perda irreversível dos ecossistemas florestais na Amazônia, também deu sinais de cooperaçáo.

Certamente a atenção que será dada ao Brasil como sede da $3^{a}$ Conferência Mundial do Meio Ambiente da ONU em junho de 1992, também contribuirá para gerar novas iniciativas quanto à aplicação de soluções internas. A ajuda financeira internacional para a proteção das florestas tropicais deverá caminhar passo a passo com uma nova estratégia nacional de desenvolvimento regional ecológico e socialmente adaptado.

\section{Referências bibliográficas}

AB'SABER, A.N. Zoneamento ecológico e econômico da Amazônia. Questōes de escala e método. Estudos Apanf̧ados (USP), v.3, n.5, p. 4-20, 1989.

ALLEGRETI, M.H. Extractive reserves: an alternative for reconciling development and environmental in Amazonia. In: ANDERSON, A.B. Alternatives to deforestation. New York, 1990, p. 252-264.

ANDERSON, A.B. Alternatives to deforestation. Steps toward sustainable use of the Amazon rain forest. New York, 1990.

BINSWANGER, H. Fiscal and legal incentives with environmental effects on the Brazilian Amazon. Washington, 1987.

BRAZILIAN INSTITUTE OF THE ENVIRONMENT AND RENEWABLE NATURAL RESOURCES. Activity Report. Brasilia, 1990.

Die entwaldung der tropen und diebth0.uswirkung auf das klima. Forstwissenschaftliches Zentrablatt, IV, p. 263-275.

BRUENIG E.F. Die crbaltung, nacbbaltige vielfacbnutzong und langfiistige entwicklung der tropischen immergrünen fruchtwoulder (Regenwälder). Hamburg, 1989.

CONSTITUINTE (ed.) Programa "Nossa Natureza" : GTI-VI- Proteçāo do meio ambiente, das comunidades indigenas e das populaçóes envolvidas no processo extrativista. Relatbrio final. Brasilia, 1989.

DEUTSCHER BUNDESTAG (Parlamento Alemão) (ed.) Schutz der crdatmosphäre. Eine internationale Herausforderung. Zwischenbericht der Enquete-Kommission des 11. Dt. Bundestages. "Vorsorge zum Schutz der Erdatmosphäre", 2a ed. ampliada. Bonn, 1989. 
Sclutz der tropisclsen Wälder. Eine internationale selbwerpunktaufgabe. Zweiter Bericht der Enquete Kommission des 11. Dt. Bundestages "Vorsorge zum Schutz der Erdatmosphäre" (Zur Sache 10/90). Bonn, 1990.

DROSTE, B.V. \& DOGSÉ, P. Debt-for-nature excluanges and biosphere reserves: experiences and potential (manuscrito). Paris, 14.8.1990.

ENGELHARDT, W. \& FITTKAU, E.J. (eds.). Tropische regenwälder - eine globale Herausforderung. Spixiann Zeitsclorift fiir Zoologie, Supplement 10, München, 1984.

FEARNSIDE, P.M. Deforestation in the Brazilian Amazon: how fast is it occuring? Interciêncin, v.2, n.2, p. 82-88.

- Environmental change and deforestation in the Brasilian Amazon. In: HEMMING, J. (ed.) Change in the Amazon Basin: man 's impact on forests and rivers, v.l. Manchester/UK., 1985, p. 70-89.

GOODLAND, R. Apaliafẵo do meio ambiente. A política ambiental nova do Banco Mundial (manuscrito). Belém, 25.10.1990.

GOODLAND, R. \& IRWIN, H.S. Amazon jungle: green bell to red desert? Developments in landscape management and urban planning, 1. Amsterdam, 1975.

GOVERNO COLLOR. Propostas e diretrizes para o meio ambiente por uma politica moderna e eficiente. Brasilia, 1990.

GUIMARÄES, R.P. Ecopolitics in the T7ird World: an institutional analysis of environmental management in Brasil. Ph.D. thesis, University of Connecticut, UMI, Ann Arbor, 1986. 89-104, 1989.

La ecopolítica en el desarrollo del Brasil. Revista de la CEPAL, n.38, p. 38;

IEA (Instituto de Estudos Avançados/USP). Projeto Floram - uma plataforma. Estudos Apangados, v.4, n.9, 1990.

KOHLHEPP, G. Stand und problematik der brasilianischen entwicklungsplanung in Amazonien. Amazomiana, v.VI, n.l p. 87-104, 1976.

Zum problem von interessenkonflikten bei der neulanderschiliebung in ländern der dritten welt. Am beispiel des brasilianischen amazonasgebietes. Frankfurter Beitriage zur Didaktik der Geographie, n.1, p. 15-31, 1977.

Amazonien. regionalentwicklung im spannungsfeld ökonomischer interessen sowie sozialer und ökologischer notwendigkeiten. Problemräume der Welt, v.8. 1987a.

Problemas do planejamento regional e do desenvolvimento regional na área do Programa Grande Carajás no Leste da Amazônia. In: KOHLHEPP, G. \& SCHRADER, A. (eds.) Homem e natureza na Amazbnia (Tübinger Beirräge zur Geographischen Lateinamerikaforschung TBGL 3), p. 313-345, $1987 \mathrm{~b}$.

Desafios à ciência e às políticas de desenvolvimento regional. Reflexóes e recomendaçōes sobre o futuro desenvolvimento da Amazônia. Estudos Avanfados, v.3, n.7, p. 183-199, 1990.

Impactos regionais de "grandes projetos" e as possibilidades de reorganização do espaço na periferia amazónica. In: ARAGON, L.E. (ed.) $A$ desordem ecológica dn Amazbnia. Série Cooperaçăo Amazônica 7, UNAMAZ, p. 253-269, 1991. 
. The destruction of the tropicalbm0. rainforests in the Amazon region of Brazil. An analysis of the causes and the current situation. Applied Geography and Development, n.38, p. 87-109, $1991 b$.

LAMPRECHT, H. Zu einnigen schwerwiegenden Irrtümern über die tropischen Regenwälder. Forstarchiv, n.60, p. 207-210, 1989.

LUTZENBERGER, J. Fim do futuro? Manifesto ecoldgico brasileiro. Porto Alegre, 1977. 155-160, 1987.

Who is destroying the Amazon rainforest? The Ecologist, v.17, n.4/5, p.

MAHAR, D.J. Frontier development policy in Brazil: a study of Amazonia. New York, 1979.

Gopernment policies and deforestation in Brazil's Amazon region. Washington, World Bank Publication, 1989.

MINISTÉRIO DO INTERIOR (MINTER), IBAMA. Programa Nossa Natureza - Leise Decretos. Brasilia, 1989.

MORAN, E.F. (ed.) Tlıe dilemma of Amazonian development. Boulder, 1983.

NITSCH, M. Die rolle der internen politisch-administrativen strkturen und der externen geldgeber bei der zerstörung tropischer wälder - der fall des brasilianischen Amazoniens. In: BÄHR, J. et. alii (eds.) Die Bedrobung der tropischen Wallder. Kiel, Kieler Geographische Schriften, 73, 1989, p. 63-85.

OBERNDÖFER, D. Schutz der tropischen regenwälber durch entschuldung. Perspektiven und Orientierungen. Schriftenreibe des Bundesknnzleramtes, n.5, p. 91-117, 1989 b.

OBERDÖFER, D. Schutz der tropischen regenwälder (Freuchtwälder) durch ökonomische Kompensation. Freiburger Universitütsblätter, n.105, p. 91-117, 1989 b.

PADUA, J.A. The birtls of green politics in Brasil: exogenous and endogenous factors (manuscrito) Rio de Janeiro, 1989. (ed.) et alii. Ecologia e politica no Brasil. Rio de Janeiro, 1987.

PADUA, M.T.J. Unidades de conservafẵo (manuscrito). Brasilia, 1988.

SACHS, I. Strattgies de l'ecodtéloppment. Paris, 1980.

SCHIPULLE, H.P. Nossa Natureza: chance für neuorientierung de brasilianischen Amazonaspolitik. Entwicklung und Zusammenarbeit, n.8/9, p. 25-29, 1989.

SIOLI, H. Recent human activities in the Brazilian Amazon region and their ecological effects. In: MEGGERS, A. \& DUCKWORTH (eds.) Tropical forest ecosystems in Africa and South America: a comparative review. Washington, 1973, p. 321-334.

gart, 1983.

Amazonien. Grundlagen der Ökologie des gröbten tropischen waldgebietes. Stutt-

UNESCO. Plan d'action pour les réserves de la biosphère. Nature et Ressources, v.20, n.4, p. 1-12, 1984.

VALVERDE, O. Grande Carajás: planejamento da destruição. Rio de Janeiro, 1989.

VIOLA, E. The ecologist movement in Brazil (1974-1986): from environmentalism to 
ecopolitics. Intcrnational Journal of Regional and Urban Research, v.12, n.2, p. 211-221, june 1988.

WEIDELT, H.-J. Die nachhaltige bewirtschaftung des tropischen feuchwaldes - Möglichkeiten und grezen. Forstarchip. n.60, p. 100-108, 1989.

WÖHLCKE, M. Die kosten des fortsclbritts und entwicklungsperspektipen in eincm sclswellenland. Brasilien, Ebenhausen, 1988.

Umwelt und ressourcenschurz in der internationale entwicklungspolitik. Probleme und zielkonflikte. Aktuelle Matcrialion zur internationalem Politik, v.23, 1990.

Gerd Kolblhepp é professor de Geografia Humana do Instituto Geográfico da Universidade de Tübingen (Alemanha).

Tradução de Monika Roper em colaboração com Lautiana Cardoso de Oliveira. Este textó foi aprovado para publicação em junho de 1992. 